Article

\title{
Skateboards as a Sustainable Recyclable Material
}

\author{
Dylan T. Willard and Joseph R. Loferski * \\ Department of Sustainable Biomaterials, Virginia Tech, Blacksburg, VA 24061, USA; dylanw3@vt.edu \\ * Correspondence: jloferski@vt.edu; Tel.: +1-540-231-4405; Fax: +1-540-231-8868
}

Received: 25 April 2018; Accepted: 11 May 2018; Published: 15 May 2018

\begin{abstract}
The exact number of skateboards manufactured every year is unknown, but it is estimated to be in the millions. Most skateboard decks are made from a high grade of maple (Acer spp.) veneer plywood and typically last only a few months before they break or deteriorate beyond use. Millions of used skateboard decks are discarded annually, ending up in landfills when, instead, they could be recycled into new products. But beyond artistic or aesthetic purposes, material properties of the used skateboard decks are unknown. The objective of this paper is to investigate the material properties of wooden composite panels created by reengineering the skateboard deck material. These aesthetically pleasing wooden panels may be a sustainable recycled product. This paper presents a method of analyzing material properties and structural aspects of used skateboard deck material. Tests were developed to measure the stiffness and strength in bending, moisture content, specific gravity, moisture durability, and species identification. The results show that this process of reengineering skateboard decks makes for a strong wood product and may be useful to those interested in developing new products from recycled materials.
\end{abstract}

Keywords: skateboard; sustainability; recycling; plywood; veneer; composite; wood composite; sugar maple; stiffness; strength; moisture content; specific gravity; delamination; moisture durability; species identification

\section{Introduction}

The Skateboard

Skateboarding is an action sport that involves riding and preforming tricks on a skateboard. Skateboarding can be a competitive or recreational sport. Skateboards are composed of three main components: the deck, trucks, and wheels. The deck is a wooden plywood material that a rider stands on. The length of a skateboard deck is often between 787-838 mm (31-33 in.) and the width can be between 196-210 mm (7.75-8.25 in.). The shape of a skateboard deck is slightly concave on the longitudinal axis, with a nose and tail that are both curved upward. Examples of the shape of a skateboard deck can be seen in Figures 1 and 2. A sheet of griptape is applied to the top of the skateboard deck to provide friction between the rider and the board. The trucks allow the skateboard to turn, serving as the axles of the skateboard. Trucks connect the wheels to the deck. Trucks vary in size. The width of the truck is typically equivalent to the width of the skateboard deck. The skateboard trucks are attached near the curved ends at the nose and tail. The wheels, which have ball bearings to reduce friction, are attached to the ends of the truck. Examples of skateboard trucks and wheels are shown in Figures 3 and 4. 


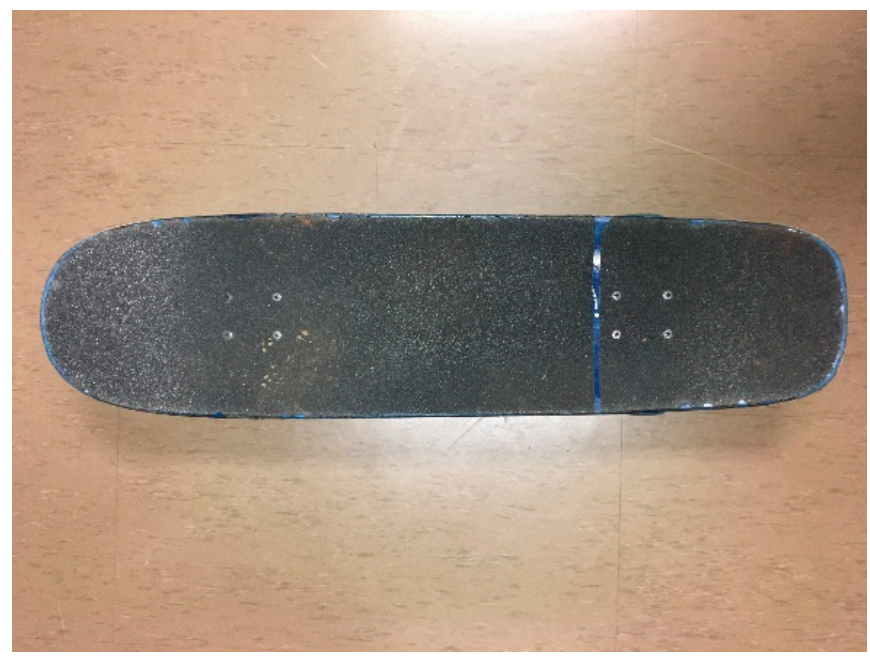

Figure 1. Skateboard Top View.

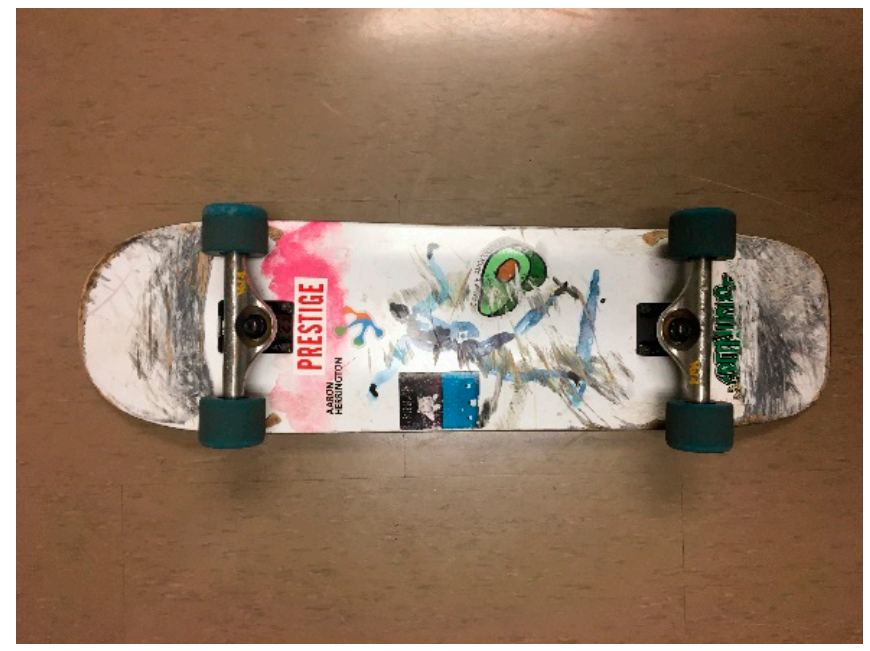

Figure 2. Skateboard Bottom View.

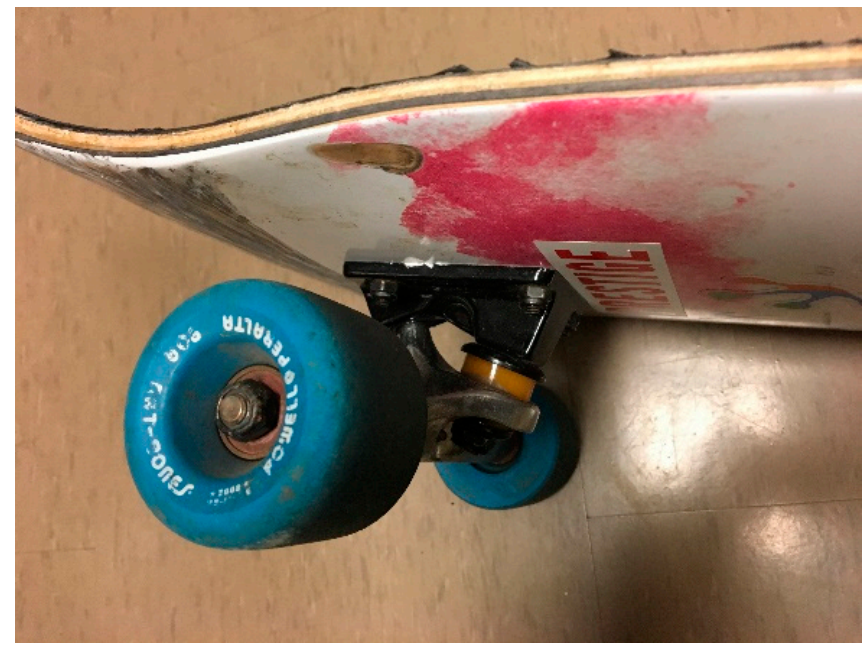

Figure 3. Skateboard Front Left Wheel. 


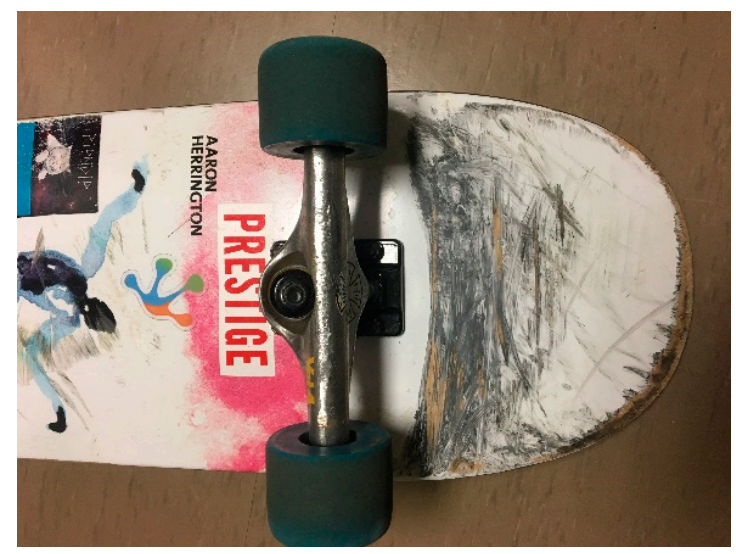

Figure 4. Skateboard Front Truck.

The skateboard deck withstands a lot of abuse during riding and even more when the rider is preforming tricks such as ollies, kickflips, or any trick in which the tail of the board hits the ground. As the skateboard ages and is used aggressively, the skateboard deck loses its elasticity, the nose and tail lose their shape or shorten due to abrasion, and the deck can even break in half. While a skateboard deck may look worn and unusable after it has served its purpose to the rider, the inner layers of plywood veneer may still retain their structural properties. Aside from abrasion that occurs on the edges of the board, most of the damage is only on the surface of the plywood. Even if the skateboard deck breaks, there may be potential for it to be recycled. This paper explores this possibility that the plywood deck can be reengineered into panels which are strong, stiff, and aesthetically pleasing.

The objectives of this paper are to;

1. Develop a process in which skateboard deck plywood material can be fabricated into panels.

2. Determine strength and stiffness in bending of strips used to make the panels.

3. Measure the moisture content and specific gravity of several used skateboard decks.

4. Determine the moisture durability of the adhesives used in the skateboard deck plywood and evaluate the propensity for splitting of veneers.

5. Identify the species of wood used in the plywood.

The goal of this project is to determine how skateboards can be used as a sustainable material. Material properties were measured to identify potential uses of recycled skateboard material.

There are three different types of veneer in skateboard decks; face veneer (top and bottom), longitudinal veneer, and perpendicular veneer. Longitudinal veneer has the orientation of the wood grain running from nose to tail on the skateboard. Face veneer is a sheet of veneer that has a longitudinal orientation, but is handpicked based on aesthetic qualities. Since the face veneer is the sheet of wood which is exposed on the bottom and top of the skateboard deck it is important to have a high grade of wood veneer with no knots and smooth grain so it is more appealing to consumers. Perpendicular veneer is veneer that has a grain orientation perpendicular to the longitudinal veneer. This provides support from side to side along the board and helps to uphold the decks concavity. The plywood is made from seven different sheets of veneer that are layered with the grain orientation, from top to bottom, as follows; face, longitudinal, perpendicular, longitudinal, perpendicular, longitudinal, and face. The longitudinal orientation of the skateboard deck is the direction that takes the largest impacts and has a significant stress in bending. That is why there are five sheets of veneer with a longitudinal orientation as opposed to two perpendicular sheets. The perpendicular veneers are often thinner than the longitudinal veneers, while maintaining symmetry about the neutral axis providing a balanced construction of the plywood. Skateboard manufactures often use aliphatic resin (wood glue) that is a nontoxic, water resistant, and a strong adhesive. They typically cold press the veneers using molds to create the upswept nose and tail and the concavity of the board. 
There are many reasons to recycle skateboards. The number of skateboards manufactured per year is unknown since industries do not publicize that information, but it is estimated in the millions [1]. For example, the skateboard deck manufacturing company, PS Stix ${ }^{\mathrm{TM}}$, owned by Paul Schmitt CEO and Founder, makes over 300,000 skateboard decks a year [1]. PS Stix ${ }^{\mathrm{TM}}$ manufactures skateboard decks for Element $^{\mathrm{TM}}, \mathrm{FA}^{\mathrm{TM}}$, Welcome ${ }^{\mathrm{TM}}$, Quasi ${ }^{\mathrm{TM}}$, Toy Machine ${ }^{\mathrm{TM}}$, and many more brands [1]. With this large number of skateboard decks being produced every year and considering the "wear and tear" they experience, many boards end up broken or thrown away. A difficulty of recycling skateboard decks is the logistics of collecting the broken/used decks in sufficient numbers to warrant a business dedicated to manufacturing products from them. Collecting skateboard decks at one large central location would be desirable but likely impractical, because most skateboarders are dispersed geographically. A possible solution could involve local skate shops, who sell skateboards, to provide a location to return broken/used skateboard decks. This would allow artisans and businesses access to a potentially sustainable resource for little or no cost. Furthermore, landfill waste would be reduced because a product that was previously discarded has now found its way in to a market of recyclable materials. With such a substantial amount of potentially usable material being discarded every year, finding a way to repurpose skateboard decks would decrease waste and provide a structural aesthetic material, which is the motivation for this project.

\section{Turning Skateboards into Wood-Based Composite Panels}

Skateboards turned into wood based composite panels, such as the ones in Figures 5 and 6 , were processed by cutting, sanding, and gluing.

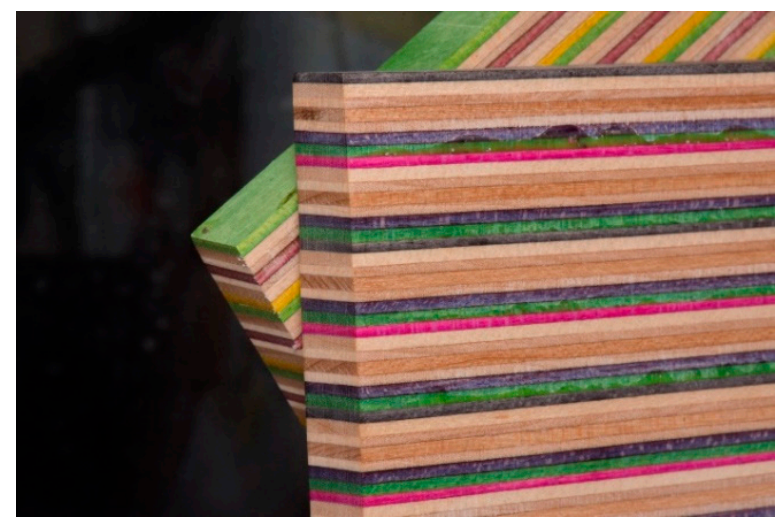

Figure 5. Composite Panels made by cutting skateboard decks into strips and gluing together.

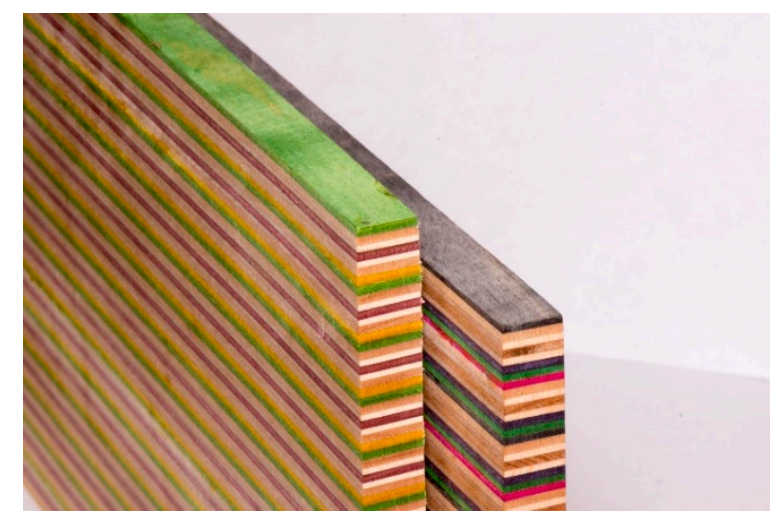

Figure 6. Another view of the composite panels in Figure 5. Note the colorful veneers dyed by the skateboard manufacturers for aesthetics. 
Details of the process follow:

1. Preparation: After initial disassembly of the trucks from the skateboard, the griptape is removed, and leftover adhesive is scraped off the top of the deck. Once completed, the deck is ready for processing.

2. Sanding: The skateboard decks were smoothed using sand paper to remove dirt, paint, hydrophobic material, or stain that may be left on the wood. Sanding also prepares the wood material for gluing.

3. Rough Sizing: Due to the awkward shape of a skateboard deck, cutting using wood working machines, such as a table saw or radial arm saw, can be difficult or dangerous. Because the board is concave, it cannot be placed flat on the bottom side of the skateboard deck. Likewise, due to the nose and tail projecting upward the board cannot lie flat on its top side. A band-saw can be used to safely remove the nose and tail from the ends, allowing the center portion to lay flat for further processing with a radial arm saw or similar tool. At this point the board is cut into three pieces: a nose, tail, and middle section. The middle section of the skateboard is used to create the panels in this project. The nose and tail can be saved for other purposes.

4. Rough cutting: After making the rough cut to remove the nose and tail, the middle portions of the deck can be cut on a radial arm saw. The nose and tail were removed in step 3, the skateboard deck can be placed top side down (i.e., concave down), which allows the board to remain stable when cutting, because the board can sit on the two parallel edges of the concave surface. The fence of the radial arm saw is perpendicular to the direction in which the saw cuts, the edge of the skateboard deck can be held against the fence and ends can be precisely cut to $90^{\circ}$. The cut made by the radial arm saw improves the rough cut previously made by the band saw and produces a rectangular middle section. The skateboard deck is now ready to be cut into strips. If the skateboard deck has suffered severe damage or has cracks, these areas can be cut off by the radial arm saw and smaller panels can be made from these zones.

5. Final Cutting: A band saw is used to cut strips out of the middle section of the board, which was made using the radial arm saw in step 4 . The band saw has a thin kerf compared to a table saw, which is an advantage when making multiple cuts, because less waste material is produced. Due to the board's concavity, the strips must be cut with square cross sections and parallel edges. If the middle section is not cut properly, the strips will have an uneven parallelogram like shape, making them difficult to process into panels. Cutting parallel to the long axis of the board (i.e., rip cutting) through the center, multiple times, helps to reduce the skew in the shape of the strip, because the cut will always be made along the high point on the arch of the board's concavity. Skateboards are manufactured in widths between 196-210 mm (7.75-8.25 in.), with the most common size of $203 \mathrm{~mm}$ ( $8 \mathrm{in}$.). If the boards are rip cut four times, each strip will be approximately $12.7 \mathrm{~mm}\left(\frac{1}{2}\right.$ in.) thick. Since the thickness of a skateboard deck is also $12.7 \mathrm{~mm}\left(\frac{1}{2} \mathrm{in}\right.$.) thick, the strips will be approximately square in cross section. This process will make 16 strips from a middle section of a skateboard deck, of which only 14 strips will be usable, because the edge strips, which were exposed during the skateboards lifetime, are rounded and damaged from usage. Once all of the strips have been cut, they are ready to be glued and pressed together.

6. Gluing: The strips are edge glued into panels, by rotating them so that the face veneers of the original skateboard deck can be glued together. This is a change in orientation from face wise to edge wise, which can be seen in Figures 7 and 8. This change in the orientation of the plywood strips provides increased load capacity and adds an aesthetic quality to the panels. Many skateboard companies dye some veneers various colors, which are exposed when the strips are reoriented in the final product of the panels. Adhesive is the applied to the face veneers of the strips, which are then clamped and left to cure for $24 \mathrm{~h}$. Aliphatic resin was used as the adhesive, because it is water resistant, non-toxic, and easy to use. 
7. Finishing: After the adhesive cured, a scraper is used to remove excess glue from the panels. A progression of abrasive sanding grits from 80 to 220 was used to smooth rough edges and imperfections. Examples of the finished product can be seen in Figures 5 and 6 .

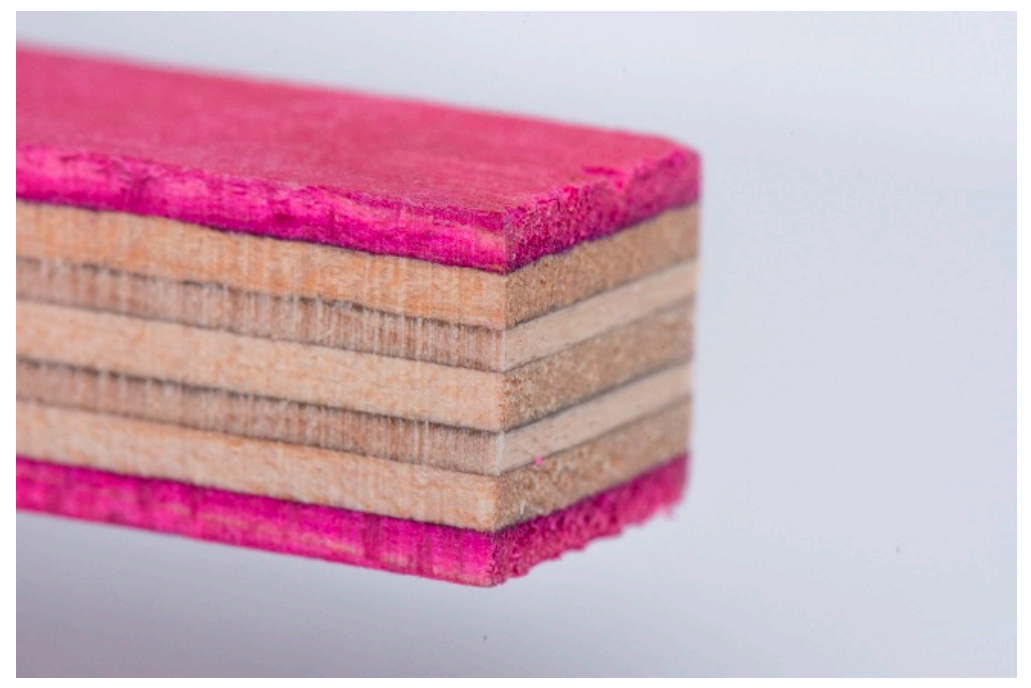

Figure 7. Face Wise Strip Orientation.

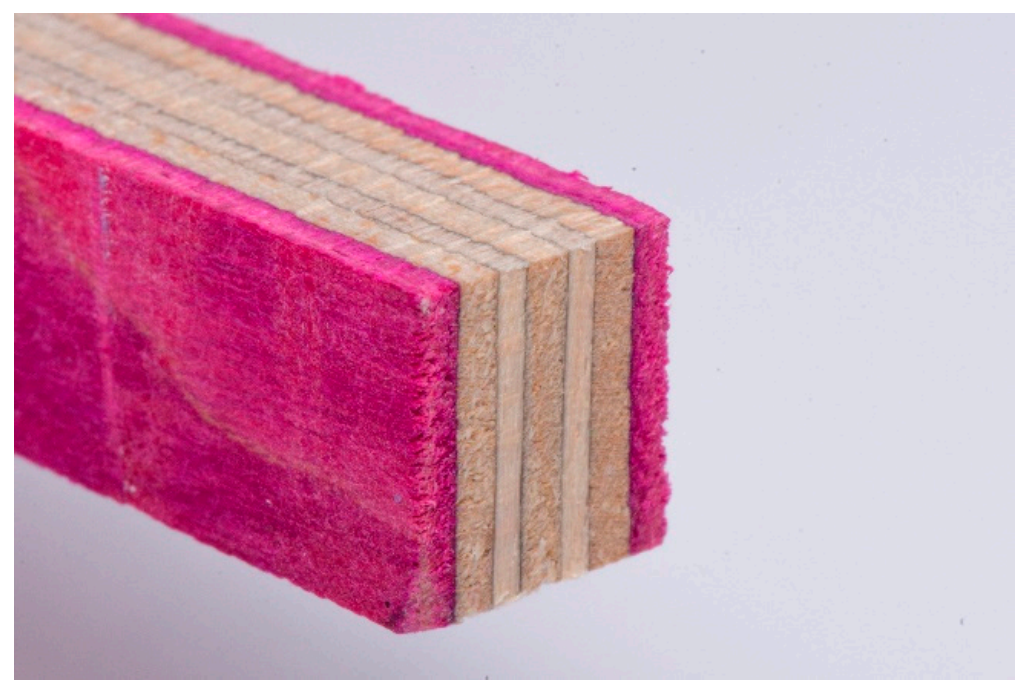

Figure 8. Edge Wise Strip Orientation.

\section{Measuring Material Properties}

\subsection{Stiffness and Strength in Bending}

To determine the stiffness and strength of used skateboard deck plywood material, samples were made from the skateboard decks which were approximately $303 \mathrm{~mm}$ (12 in.) long (longitudinal direction of the face veneer) and $12.7 \mathrm{~mm}(0.5 \mathrm{in}$.) by $12.7 \mathrm{~mm}(0.5 \mathrm{in}$.) in cross section (d). The samples were tested in third point bending to failure using a MTS Systems Corporation ${ }^{\mathrm{TM}} 22,000 \mathrm{~kg}(10,000 \mathrm{lbs}$.) capacity computer controlled testing machine over a span (L) of $254 \mathrm{~mm}(10 \mathrm{in}$.) $(\mathrm{L} / \mathrm{d}=20)$, where the load points were $95.3 \mathrm{~mm}$ (3.75 in.) apart. The advantage of third point bending is that it provides a greater distribution of stress over a larger area than center point bending. Figures 9 and 10 show the testing arrangement. 
Two material properties were measured, the stiffness (EI) and moment at failure (FS), which is a measure of strength. A computer data acquisition system continuously recorded load and deformation during the test. Load was measured by an electronic load cell and deflection was recorded by a $25.4 \mathrm{~mm}$ (1 in.) travel LVTD (Linear Variable Differential Transducer). Stiffness of the board is used to calculate deflection for a given load in a linear range of the stress/strain behavior.

Stiffness (EI) is computed by the following formula:

$$
\mathrm{EI}=\mathrm{Pa}\left(3 \mathrm{~L}^{2}-4 \mathrm{a}^{2}\right) /(24 \times \Delta)
$$

where: $\mathrm{EI}=$ Stiffness $\left(\mathrm{kg}-\mathrm{mm}^{2}\right)$ or $\left(\mathrm{lbs}-\mathrm{in}^{2}\right)$

$\mathrm{P}=\mathrm{Q} / 2$ = The load at each load point $(\mathrm{kg})$ or (lbs.)

$\mathrm{Q}=$ Total load in the linear range below proportional limit $(\mathrm{kg})$ or $(\mathrm{lbs}$.

$\mathrm{L}=$ Span $(\mathrm{mm})$ or (in.)

$\mathrm{a}=$ Distance between load points $(\mathrm{mm})$ or (in)

$\Delta=$ Deflection at load $\mathrm{Q}(\mathrm{mm})$ or (in)

Moment (FS) is computed by the following formula:

$$
\mathrm{FS}=\mathrm{M}_{\mathrm{Max}}
$$

where: FS = Maximum Moment (kg-mm) or (lbs.-in.)

$\mathrm{F}=$ Stress at failure (kpa) or (psi.)

$\mathrm{S}=$ Section modulus $\left(\mathrm{mm}^{3}\right)$ or $\left(\right.$ in. $\left.^{3}\right)$

$\mathrm{M}_{\mathrm{Max}}=\mathrm{P}_{\mathrm{Max}} \times \mathrm{L} / 3$ (mm-kg) or (in.-lbs.)

$\mathrm{P}_{\text {Max }}=\mathrm{Q}_{\text {Max }} / 2=$ Maximum at each load point

$\mathrm{Q}_{\mathrm{Max}}=$ Total maximum load measured by load cell (kg) or (lbs.)

$\mathrm{L}=$ Span (mm) or (in.)

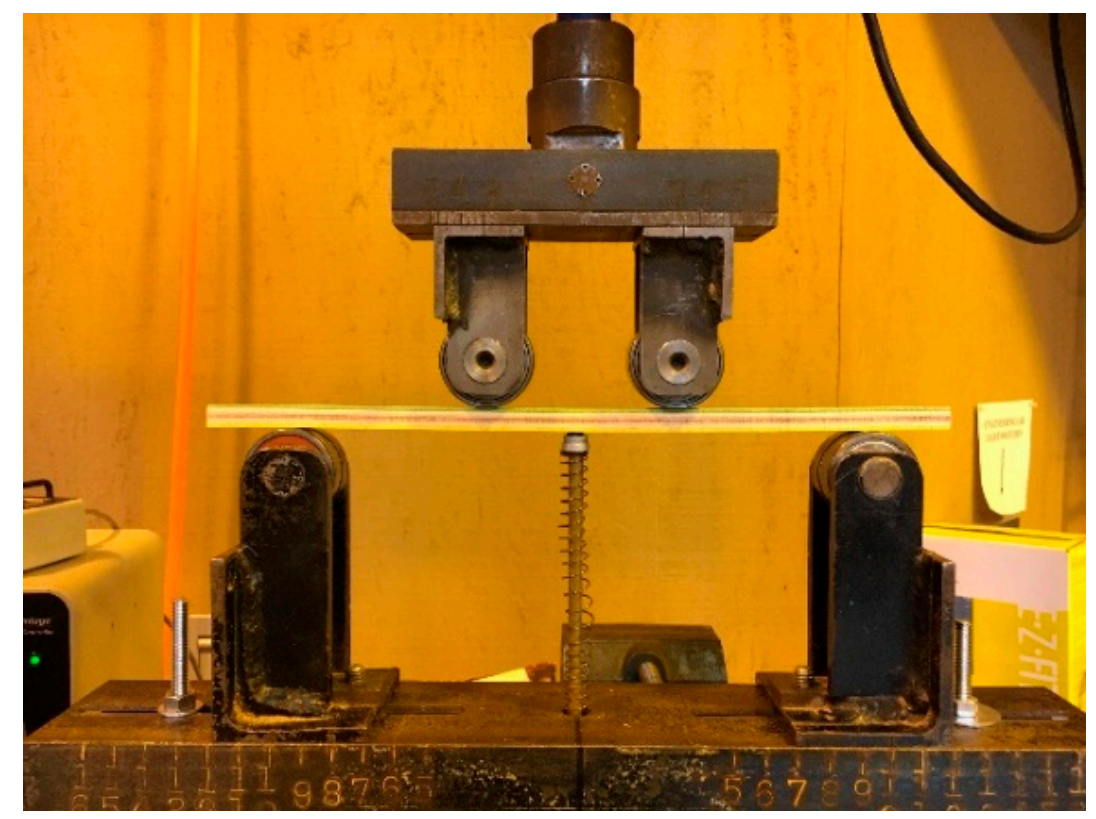

Figure 9. Third point bending setup in the face wise direction showing load points and linear variable differential transformer (LVDT) measuring deflection at center line. 


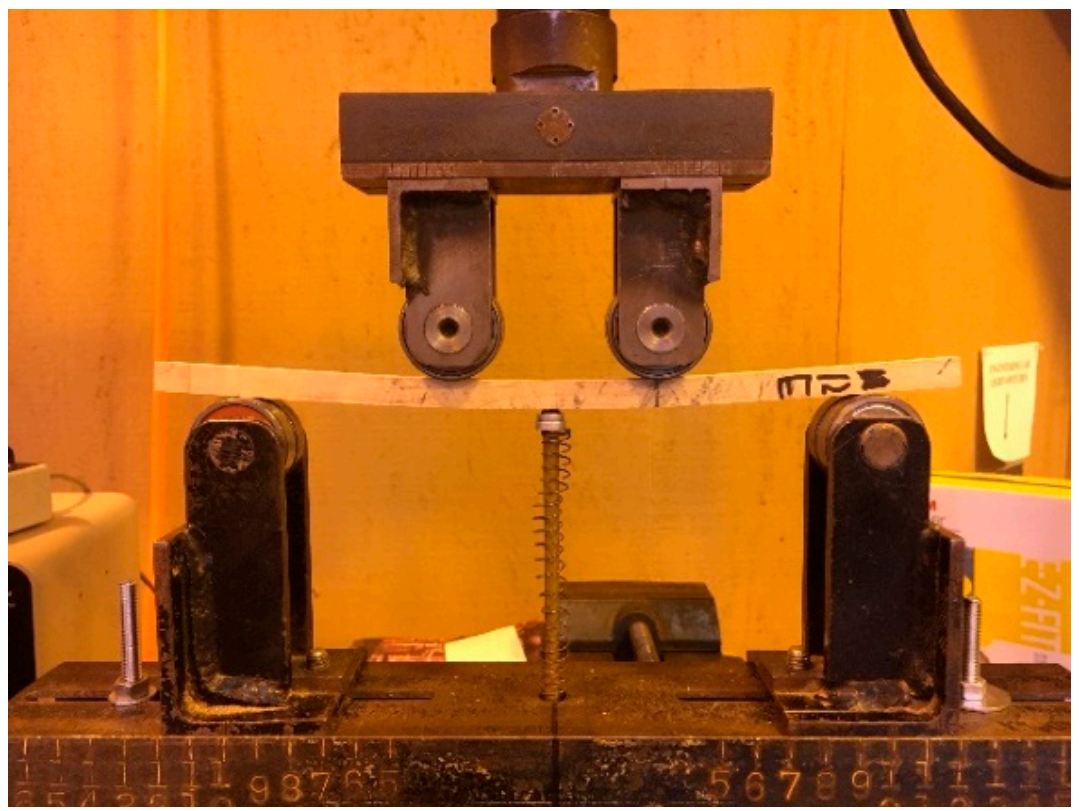

Figure 10. Third point bending setup in the edge wise direction showing load points and LVDT measuring deflection at centerline.

Two orientations of the plywood strips were tested, where force was applied parallel to the width (edge wise) and parallel to the thickness where the face grain is parallel to the span (face wise) as shown in Figures 7-10. This provided data on the board strength and stiffness parallel and perpendicular to the axis of the plywood. Because the strips in the panels are orientated from face wise to edge wise during the assembly of the panels (Figures 7 and 8), tests were done in both directions to compare material properties. The results of face wise orientation are shown in Table 1 . The average stiffness face wise was 1,095,000 kg-mm ${ }^{2}$ (3740.9 lbs-in. ${ }^{2}$ ) and the strength was $1840 \mathrm{~kg}-\mathrm{m}$ (159.7 lbs.-in.). The results of edge wise orientation are shown in Table 2 . The average stiffness face wise was $1,396,000 \mathrm{~kg}-\mathrm{mm}^{2}$ (4771.2 lbs-in. ${ }^{2}$ ) and the strength was $2112 \mathrm{~kg}-\mathrm{mm}$ (183.3 lbs.-in.).

Table 1. Maximum Load at failure, Strength, and stiffness of Face Wise Strips tested in bending.

\begin{tabular}{|c|c|c|c|c|c|c|}
\hline $\begin{array}{l}\text { Sample } \\
\text { Number }\end{array}$ & $\begin{array}{l}Q_{\text {Max }} \\
\text { (lbs.) }\end{array}$ & $\begin{array}{c}Q_{\text {Max }} \\
(\mathrm{kg})\end{array}$ & $\begin{array}{c}\text { FS } \\
\text { (lbs.-in.) }\end{array}$ & $\begin{array}{c}\text { FS } \\
(\mathrm{kg}-\mathrm{mm})\end{array}$ & $\begin{array}{c}\text { EI } \\
\left(\text { lbs-in. }{ }^{2}\right)\end{array}$ & $\underset{\left(\mathrm{kg}-\mathrm{mm}^{2}\right)}{\mathrm{EI}}$ \\
\hline $1 \mathrm{~F}$ & 105.6 & 47.9 & 178.2 & 2053 & 4336 & $1,269,000$ \\
\hline $2 \mathrm{~F}$ & 98.1 & 44.5 & 165.6 & 1908 & 4018 & $1,176,000$ \\
\hline $3 F$ & 99.5 & 45.1 & 167.9 & 1934 & 4201 & $1,229,000$ \\
\hline $4 \mathrm{~F}$ & 66.5 & 30.2 & 112.2 & 1293 & 3354 & 982,000 \\
\hline $5 \mathrm{~F}$ & 78.6 & 35.7 & 132.7 & 1529 & 3332 & 975,000 \\
\hline $6 \mathrm{~F}$ & 89.6 & 40.6 & 151.2 & 1742 & 793 & 232,000 \\
\hline $7 F$ & 119.4 & 54.2 & 201.5 & 2322 & 4948 & $1,448,000$ \\
\hline $8 \mathrm{~F}$ & 99.7 & 45.2 & 168.2 & 1938 & 4946 & $1,447,000$ \\
\hline Face Wise & \multicolumn{2}{|c|}{ Average } & \multicolumn{2}{|c|}{ STDV } & \multicolumn{2}{|c|}{$\operatorname{COV}(\%)$} \\
\hline EI (lbs-in. $\left.{ }^{2}\right)$ & \multicolumn{2}{|c|}{3741} & \multicolumn{2}{|c|}{1253} & \multicolumn{2}{|c|}{33.5} \\
\hline $\mathrm{EI}\left(\mathrm{kg}-\mathrm{mm}^{2}\right)$ & \multicolumn{2}{|c|}{$1,095,000$} & \multicolumn{2}{|c|}{367,000} & \\
\hline FS (lbs.-in.) & \multicolumn{2}{|c|}{159.7} & \multicolumn{2}{|c|}{25.79} & \multicolumn{2}{|c|}{16.1} \\
\hline FS (kg-mm) & \multicolumn{2}{|c|}{1840} & \multicolumn{2}{|c|}{297} & & \\
\hline
\end{tabular}


Table 2. Maximum Load at failure, Strength, and stiffness of Edge Wise Strips tested in bending.

\begin{tabular}{|c|c|c|c|c|c|c|}
\hline $\begin{array}{l}\text { Sample } \\
\text { Number }\end{array}$ & $\begin{array}{c}Q_{\text {Max }} \\
\text { (lbs.) }\end{array}$ & $\begin{array}{c}Q_{\text {Max }} \\
(\mathbf{k g})\end{array}$ & $\begin{array}{c}\text { FS } \\
\text { (lbs.-in.) }\end{array}$ & $\begin{array}{c}\text { FS } \\
(\mathrm{kg}-\mathrm{mm})\end{array}$ & $\begin{array}{c}\text { EI } \\
\left(\text { lbs-in. }^{2}\right)\end{array}$ & $\begin{array}{c}\text { EI } \\
\left(\mathrm{kg}-\mathrm{mm}^{2}\right)\end{array}$ \\
\hline $9 \mathrm{E}$ & 116.1 & 52.7 & 196 & 2258 & 4950 & $1,449,000$ \\
\hline $10 \mathrm{E}$ & 113 & 51.3 & 190.7 & 2197 & 4707 & $1,377,000$ \\
\hline $11 \mathrm{E}$ & 118.8 & 53.9 & 200.4 & 2309 & 5122 & $1,499,000$ \\
\hline $12 \mathrm{E}$ & 119.7 & 54.3 & 201.9 & 2326 & 5254 & $1,538,000$ \\
\hline $13 \mathrm{E}$ & 105 & 47.6 & 177.2 & 2042 & 4407 & $1,290,000$ \\
\hline $14 \mathrm{E}$ & 116.7 & 52.9 & 196.9 & 2269 & 5486 & $1,605,000$ \\
\hline $15 \mathrm{E}$ & 113.6 & 51.5 & 191.6 & 2207 & 4728 & $1,384,000$ \\
\hline $16 \mathrm{E}$ & 102.8 & 46.6 & 173.5 & 1999 & 5084 & $1,488,000$ \\
\hline $17 \mathrm{E}$ & 75.3 & 34.2 & 127.1 & 1464 & 3181 & 931,000 \\
\hline $18 \mathrm{E}$ & 73.9 & 33.5 & 124.7 & 1437 & 2996 & 877,000 \\
\hline $19 \mathrm{E}$ & 110.7 & 50.2 & 186.7 & 2151 & 5032 & $1,473,000$ \\
\hline $20 \mathrm{E}$ & 121.4 & 55.1 & 204.9 & 2361 & 5137 & $1,503,000$ \\
\hline $21 \mathrm{E}$ & 117.2 & 53.2 & 197.8 & 2279 & 5419 & $1,586,000$ \\
\hline $22 \mathrm{E}$ & 105.2 & 47.7 & 177.6 & 2046 & 4689 & $1,372,000$ \\
\hline $23 \mathrm{E}$ & 119.8 & 54.3 & 202.2 & 2330 & 5376 & $1,573,000$ \\
\hline Edge Wise & \multicolumn{2}{|c|}{ Average } & \multicolumn{2}{|c|}{ STDV } & \multicolumn{2}{|c|}{$\operatorname{COV}(\%)$} \\
\hline EI (lbs-in. $\left.{ }^{2}\right)$ & \multicolumn{2}{|c|}{4771} & \multicolumn{2}{|c|}{721.6} & \multicolumn{2}{|c|}{15.1} \\
\hline $\mathrm{EI}\left(\mathrm{kg}-\mathrm{mm}^{2}\right)$ & \multicolumn{2}{|c|}{$1,396,000$} & \multicolumn{2}{|c|}{21,100} & \multirow{2}{*}{\multicolumn{2}{|c|}{13.3}} \\
\hline FS (lbs.-in.) & \multicolumn{2}{|c|}{183.3} & \multicolumn{2}{|c|}{24.39} & & \\
\hline FS (kg-mm) & & & & & \multicolumn{2}{|c|}{13.3} \\
\hline
\end{tabular}

\subsection{Moisture Content and Specific Gravity}

Moisture content (MC) and specific gravity (SG) were measured according to ASTM D 4442 [2] and ASTM D 2395 [3] on 12 samples of skateboard decks. The samples were approximately $76.2 \mathrm{~mm}$ ( 3 in.) long by $102 \mathrm{~mm}$ ( 4 in.) wide and were weighed to the nearest $0.01 \mathrm{~g}$ before placing them in the oven. After $24 \mathrm{~h}$ in the oven, the oven dry mass of the samples was recorded and the volume was measured by the water immersion method using paraffin wax coating to minimize water absorption into the sample. Specify gravity was measured using oven dry mass and oven dry volume.

Moisture content was calculated according to Equation (3):

$$
\mathrm{MC} \%=(\mathrm{AD}-\mathrm{OD}) / \mathrm{OD} \times 100
$$

where:

MC $\%=$ Moisture Content in Percent

$\mathrm{AD}=$ Air Dry initial Mass (g)

$\mathrm{OD}=$ Oven Dry Mass $(\mathrm{g})$

The MC results are in Table 3. The mean MC was $9.76 \%$, standard deviation (STDV) was $1.07 \%$, and the coefficient of variation (COV) was $11.0 \%$. The MC ranged from $6.4 \%$ to $10.5 \%$.

Specific gravity was then calculated according to Equation (4):

$$
\mathrm{SG}=(\mathrm{OD} / \mathrm{V}) / \mathrm{D}
$$

where:

$\mathrm{SG}=$ Specific Gravity

$\mathrm{V}=$ Volume $\left(\mathrm{cm}^{3}\right)$

$\mathrm{D}=$ Density of Water $\left(1 \mathrm{~g} / \mathrm{cm}^{3}\right)$

The SG results are in Table 3. The mean SG was 0.72, standard deviation was 0.018, and the coefficient of variation was $2.5 \%$. The SG ranged from 0.698 to 0.755 . 
Table 3. Moisture Content and Specific Gravity Data.

\begin{tabular}{ccc}
\hline Sample Number & Moisture Content \% & Specific Gravity \\
\hline 1 & 10.12 & 0.714 \\
2 & 10.09 & 0.699 \\
3 & 10.1 & 0.711 \\
4 & 10.14 & 0.712 \\
5 & 9.72 & 0.745 \\
6 & 9.72 & 0.749 \\
7 & 6.36 & 0.755 \\
8 & 9.35 & 0.728 \\
9 & 10.44 & 0.698 \\
10 & 10.22 & 0.709 \\
11 & 10.46 & 0.716 \\
12 & 10.33 & 0.712 \\
Moisture Content Average & 9.76 \\
Moisture Content STVD & 1.07 \\
Moisture Content COV \% & 10.97 \\
Specific Gravity Average & 0.721 \\
Specific Gravity STVD & 0.0183 \\
Specific Gravity COV \% & 2.541 \\
\hline
\end{tabular}

\subsection{Moisture Durability}

The moisture durability of the skateboard deck was tested using ANSI/HVPA EF 2009 [4] soak/dry test except the soak times were modified. The purpose of this test is to determine the moisture resistance of the adhesive and skateboard deck plywood material. Defects such as delamination and splitting of the veneers were evaluated. Four different skateboard decks were tested. The test uses a $4 \mathrm{~h}$ soak and $24 \mathrm{~h}$ dry cycle at $53^{\circ} \mathrm{C}$. The second cycle uses a $24 \mathrm{~h}$ soak and a $24 \mathrm{~h}$ dry cycle at $53^{\circ} \mathrm{C}$. At the end of each cycle the samples are evaluated for delamination, splits, and surface checks.

"The sample is considered as failing when any single delamination between two plies is greater than $50.8 \mathrm{~mm}$ ( $2 \mathrm{in}$.) long, more than $6.35 \mathrm{~mm}(0.25 \mathrm{in}$.) deep and $0.076 \mathrm{~mm}(0.003 \mathrm{in})$. in width as determined with a feeler gauge."

(ANSI/HVPA EF 2009 [4]).

The MC after each cycle was computed. The data was entered into a spreadsheet and is shown in Table 4. After completing the test, all of the samples warped and split, as seen in Figures 11 and 12, which show the top and bottom surfaces after the test. Two of the samples (samples 2 and 4 ) delaminated and failed the test (Figures 13-16). Moisture contents of the samples and failure evaluation can be seen in Table 4.

Table 4. Moisture Durability Test.

\begin{tabular}{ccccccc}
\hline $\begin{array}{c}\text { Sample } \\
\text { Number }\end{array}$ & $\begin{array}{c}\text { Initial } \\
\text { Moisture } \\
\text { Content (\%) }\end{array}$ & $\begin{array}{c}\text { MC After 4 h } \\
\text { Soak/24 h Dry } \\
\mathbf{( \% )}\end{array}$ & $\begin{array}{c}\text { MC After 24 h } \\
\text { Soak/24 h Dry } \\
\mathbf{( \% )}\end{array}$ & $\begin{array}{c}\text { Delamination } \\
\text { (Yes/No) }\end{array}$ & $\begin{array}{c}\text { Top Split } \\
\text { (Yes/No) }\end{array}$ & $\begin{array}{c}\text { Bottom } \\
\text { Split } \\
\text { (Yes/No) }\end{array}$ \\
\hline 1 & 6.96 & 5 & 4.78 & No & Yes & Yes \\
2 & 6.34 & 4.23 & 4.23 & Yes & Yes & Yes \\
3 & 6.18 & 4 & 3.89 & No & Yes & Yes \\
4 & 5.66 & 3.93 & 3.58 & Yes & Yes & Yes \\
\hline
\end{tabular}




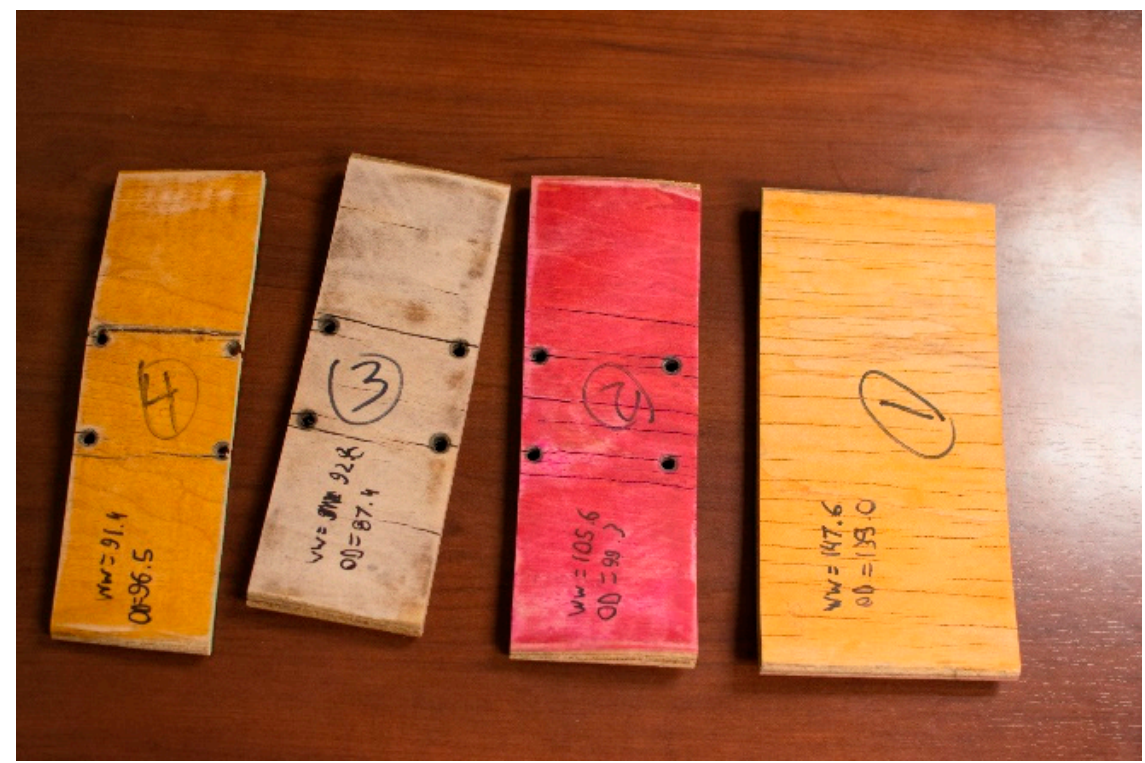

Figure 11. Top view of samples after soak/dry moisture durability test (ANSI/HVPA EF 2009 [4]).

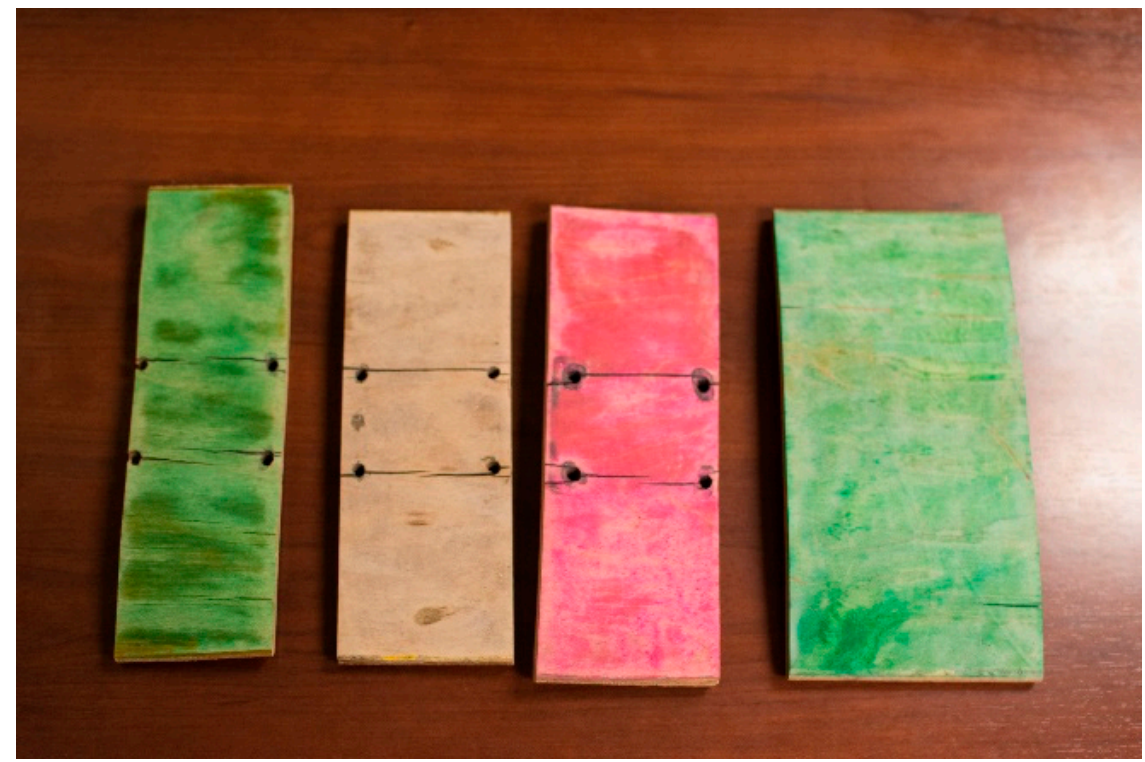

Figure 12. Bottom view of samples after soak/dry moisture durability test (ANSI/HVPA EF 2009 [4]).

Samples 2 and 4 delaminated, as seen in Figures 13-16 and therefore failed the test. Failure in sample 4 occurred in the adhesive. Failure in sample 2 occurred in both the adhesive and in the wood. Normally, when stressed, an adhesive bond has $100 \%$ wood failure and no delamination. Failure should occur in the wood because the adhesive should be stronger than the wood itself. Therefore, the adhesives used in samples 1 and 3 had good water resistance and samples 2 and 4 had poor water resistance.

Delamination can be detrimental to the recycled skateboard panels. If the panels are exposed to a high moisture environment, delamination could occur because of the poor moisture resistance of the adhesive which was used by the original skateboard deck manufacturer. The panels can be finished with a water resistant material such as polyurethane, to minimize damage from moisture. Testing the moisture durability with the simple soak/dry test can identify plywood material suitable for dry or high moisture environments. 


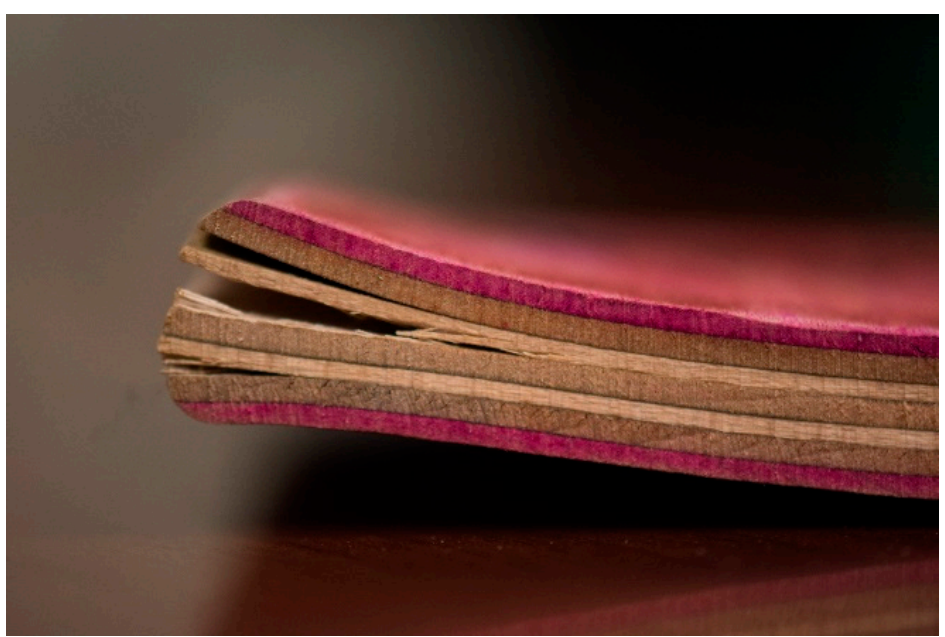

Figure 13. Cross section view of sample 2 showing delamination after soak/dry moisture durability test (ANSI/HVPA EF 2009 [4]).

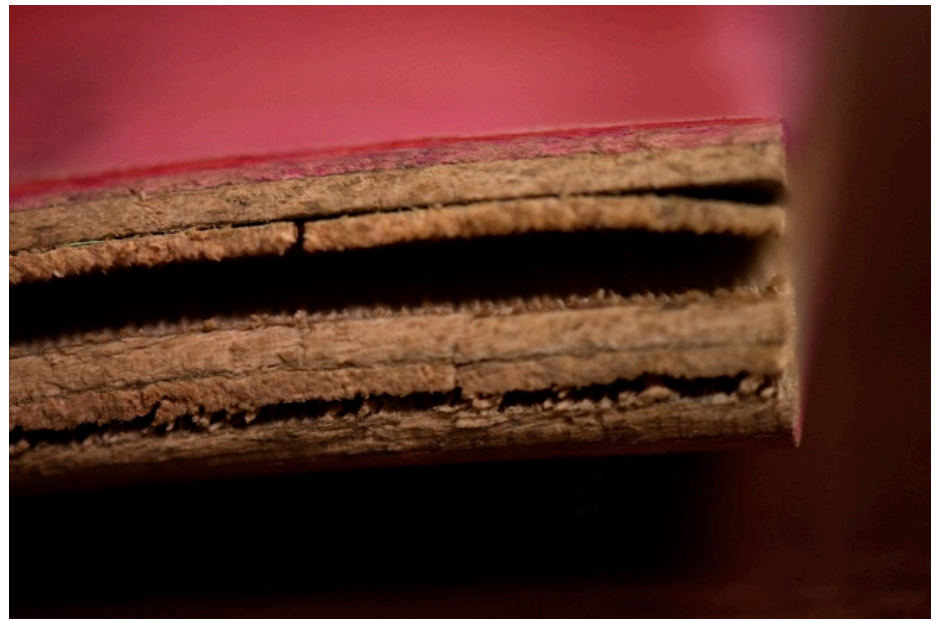

Figure 14. Face wise close up view of sample 2 showing delamination after soak/dry moisture durability test (ANSI/HVPA EF 2009 [4]).

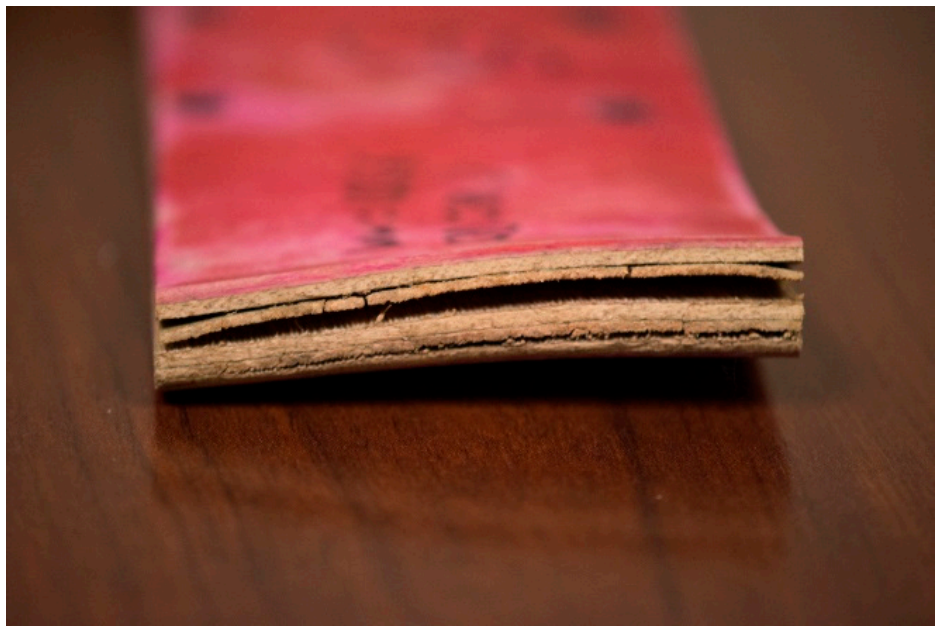

Figure 15. Face wise wide view of sample 2 showing delamination after soak/dry moisture durability test (ANSI/HVPA EF 2009 [4]). 


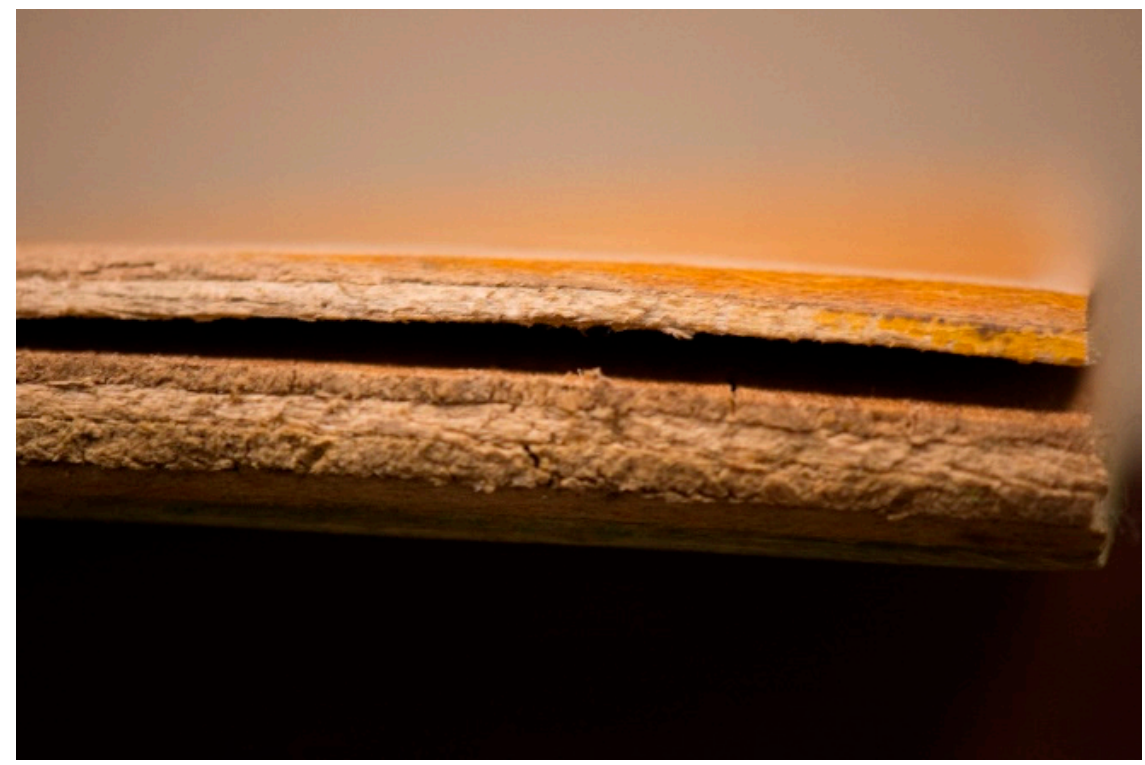

Figure 16. Face wise view of sample 4 showing delamination after soak/dry moisture durability test (ANSI/HVPA EF 2009 [4]).

Splitting parallel to the grain occurred in each sample penetrating through the first two layers of longitudinal veneer, as seen in Figures 17 and 18. Because the grain of the top two veneers and bottom two veneers is orientated parallel to the length of the skateboard, formations of splits due to shrinkage are not restrained by a cross veneer. Therefore, splits that occur in the top two layers of veneer stop when they reach the perpendicular veneer (Figures 17 and 18). In sample 4, there was one case where a split penetrated through the perpendicular cross veneer and into the middle of longitudinal veneer, as seen in Figures 19 and 20. The split occurred where the skateboard trucks were installed. This area is highly stressed while the skateboard is in use and the holes which are drilled through the plywood also weaken the surrounding area.

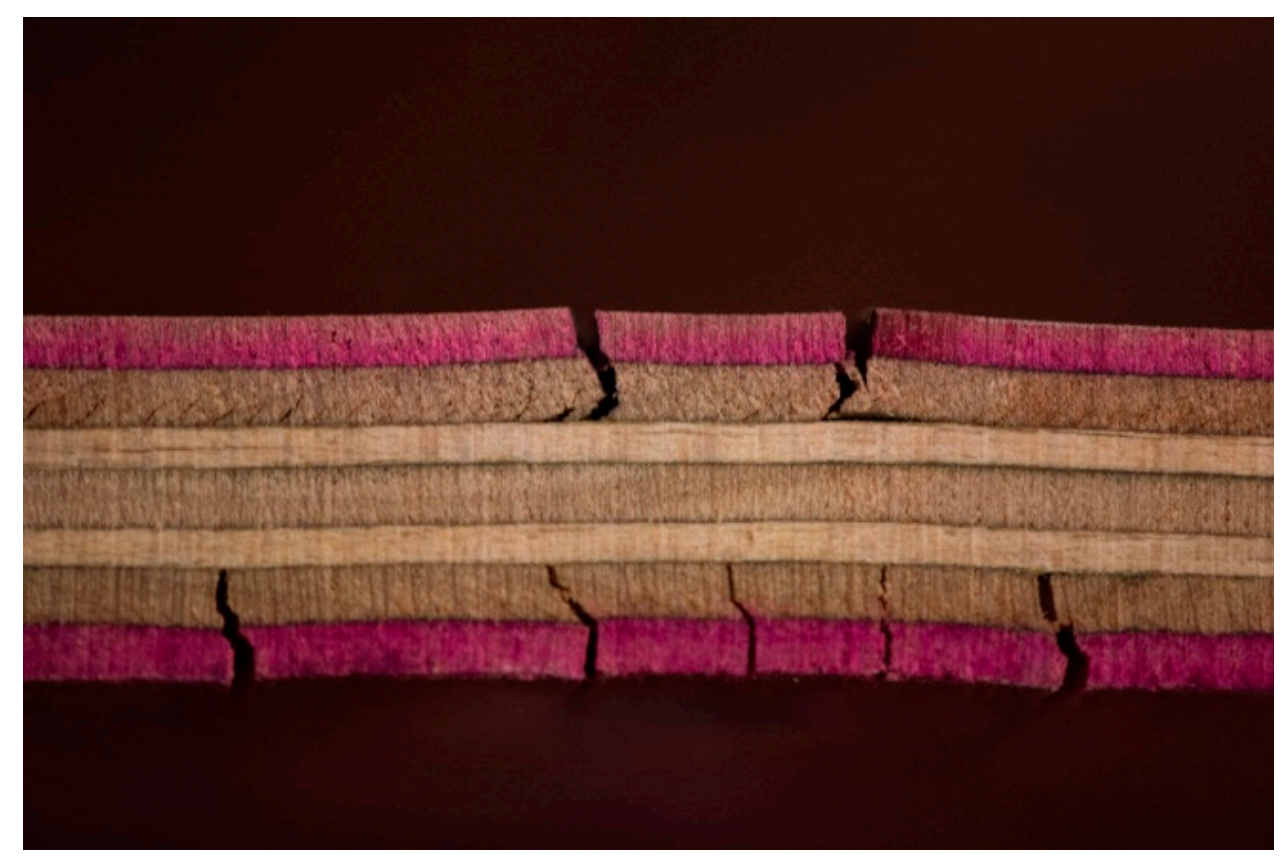

Figure 17. Cross Section View Showing Splitting in Sample 2. 


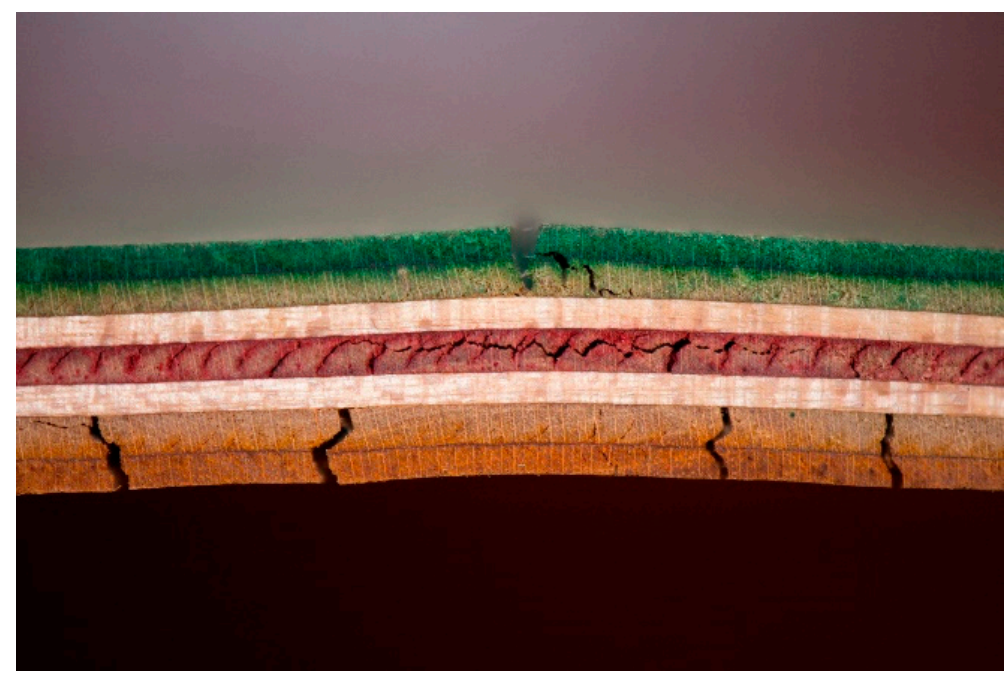

Figure 18. Cross Section View Showing Splitting in Sample 3.

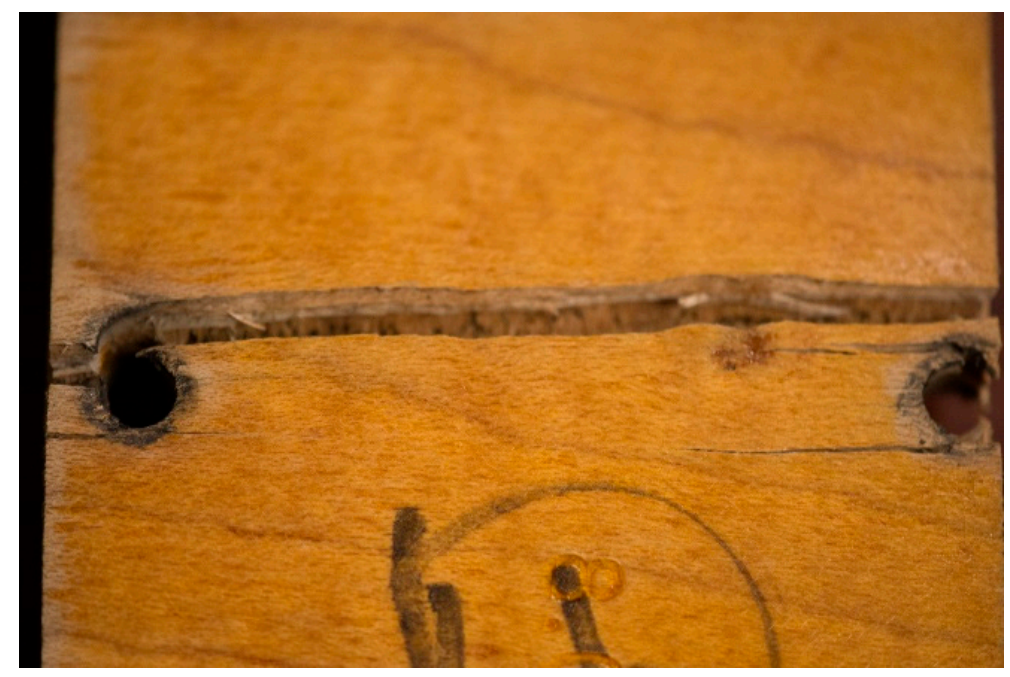

Figure 19. Top View Showing Splitting in Sample 1.

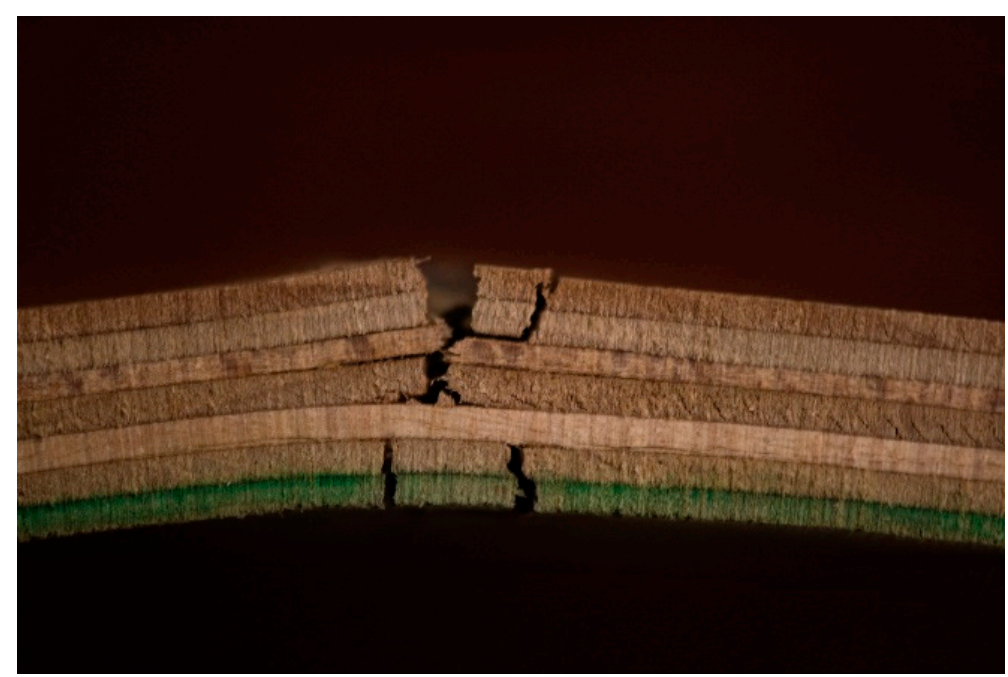

Figure 20. Cross Section View Showing Four Layer Split in Sample 1. 


\subsection{Species Identification}

The most common type of wood used to make skateboards is sugar maple (Acer saccharum). Sugar maple is used because it is a very stiff and strong wood with an average specific gravity of 0.63 [5], it works well with aliphatic resin adhesives [6], and is abundant in North America. Microscopic wood identification techniques were used to confirm that the wood in the skateboards used in this project was sugar maple. Samples from five different boards were examined.

First, a stereo microscope was used at lower magnification $(10 \times$ to $40 \times)$ to view the general characteristics of the wood. A razorblade was used to make a clean cut through the cross section of the plywood to reveal the wood anatomy. Figures 21-24 show the cross sections of two parallel longitudinal veneers, which are the top and bottom veneers. Several anatomical features were used to confirm that all of the boards were made of sugar maple including; the wood is a diffuse porous hardwood with uniseriate and multiseriate rays of two sizes, larger rays that are approximately the same width as the vessel diameter and the smaller rays that are barely visible at low magnifications, and most of the vessels are solitary as compared to red maple, which often has radial multiples of vessels up to four cells wide [5]. Color was not used as an identification feature because veneers in the skateboard decks are often dyed to vivid colors for marketing purposes.

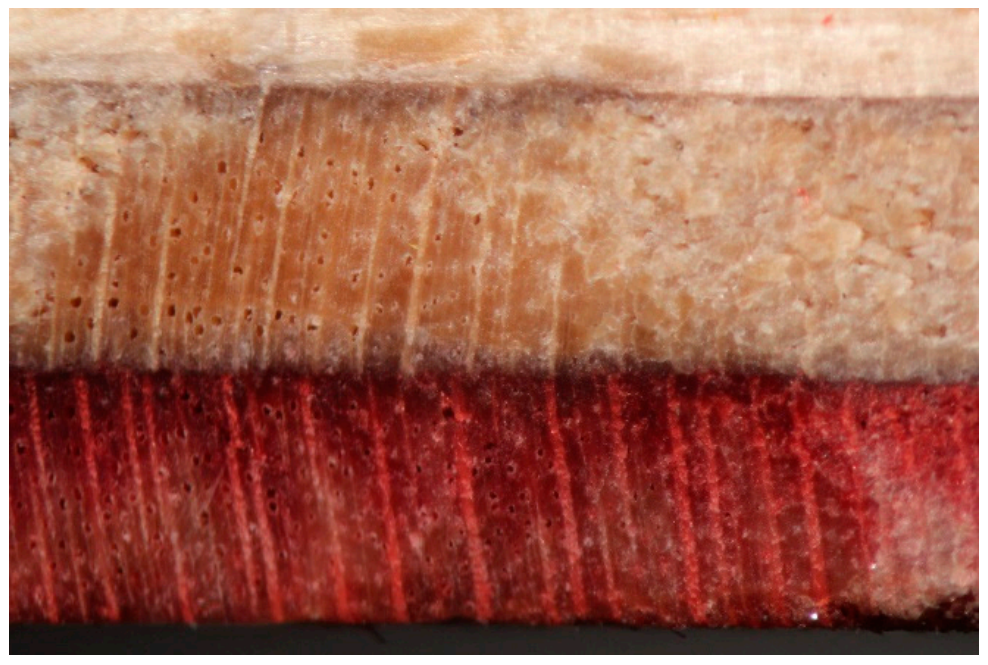

Figure 21. Species Identification Sample $120 \times$.

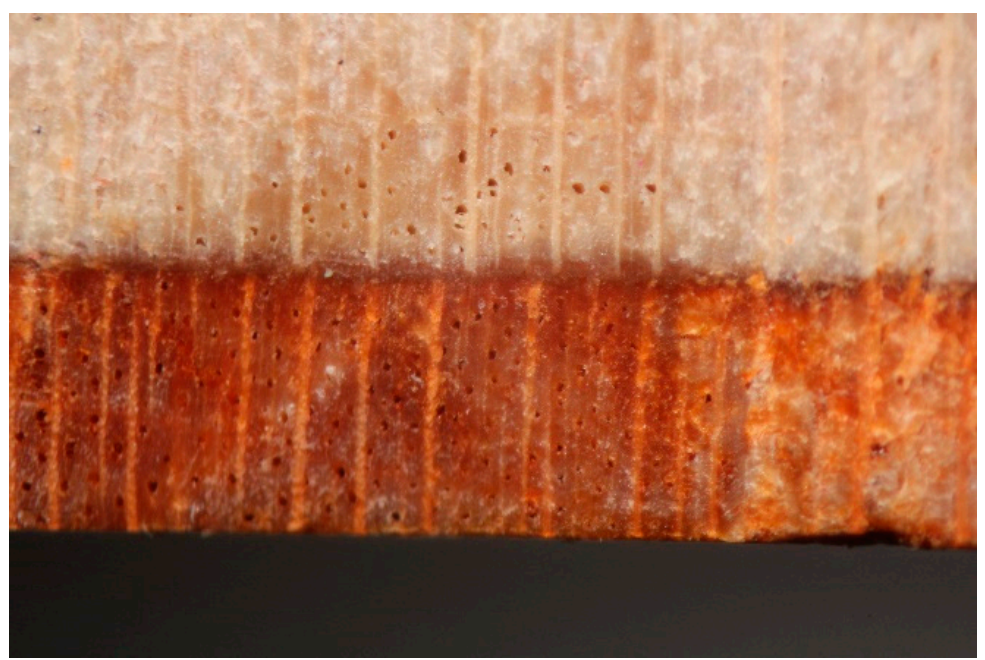

Figure 22. Species Identification Sample $220 \times$. 


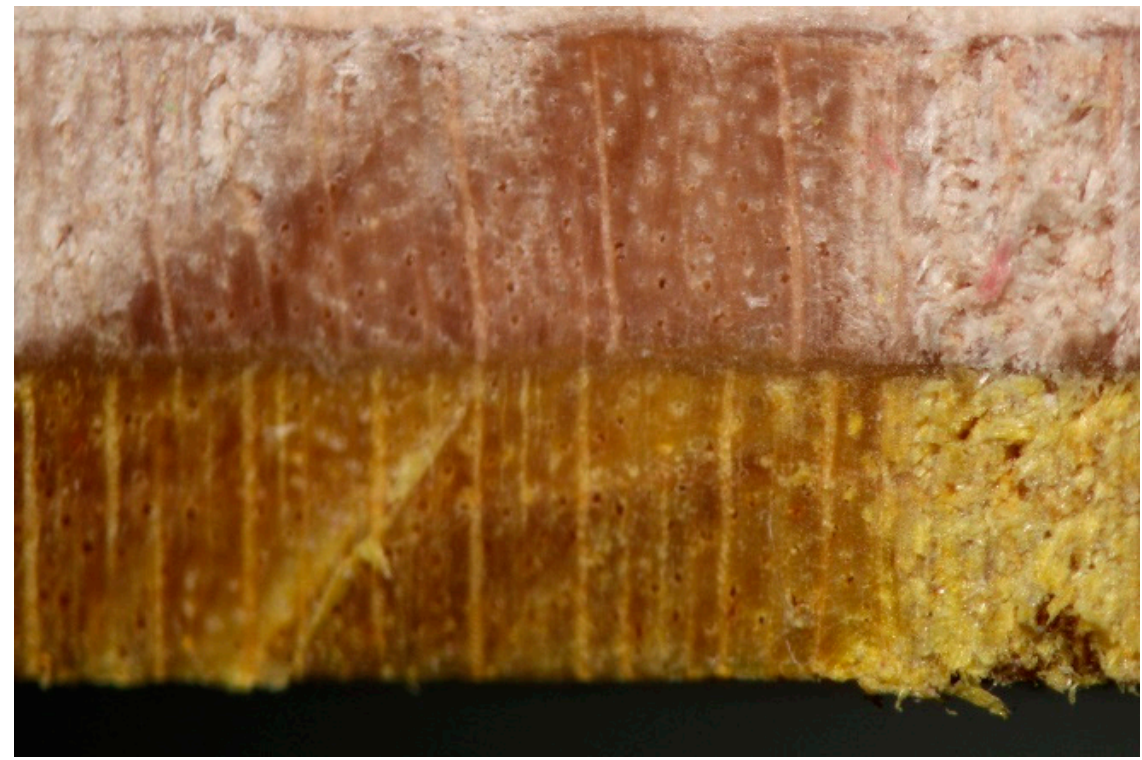

Figure 23. Species Identification Sample $320 \times$.

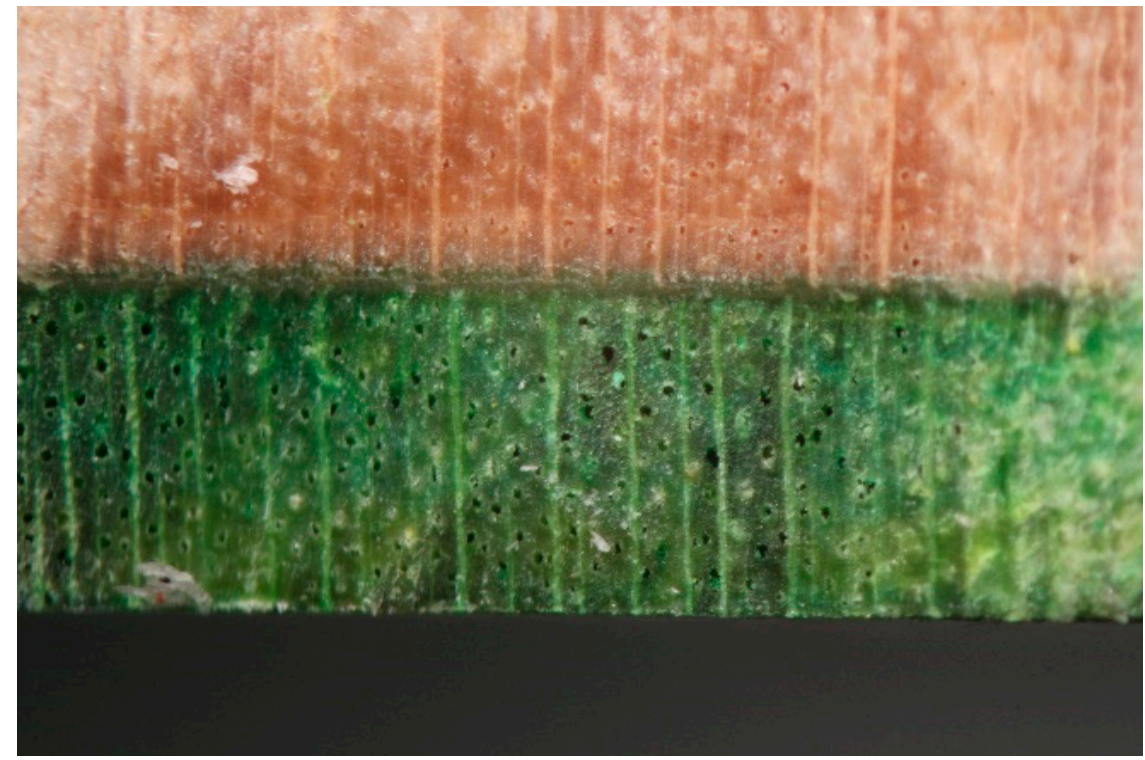

Figure 24. Species Identification Sample $420 \times$.

The species was also identified using higher magnification $(100 \times$ to $400 \times)$ with a compound light microscope. Samples were prepared by producing a thin layer $(10 \mu \mathrm{m})$ through the tangential face using a microtome. The samples were placed on a glass microscope slide, with a drop of water and a glass cover slip. Microscopic features such as alternate intervessel pitting, simple perforation plates, and spiral thickenings were observed at $100 \times$ and $400 \times$ magnification and are shown in Figures 25 and 26. 


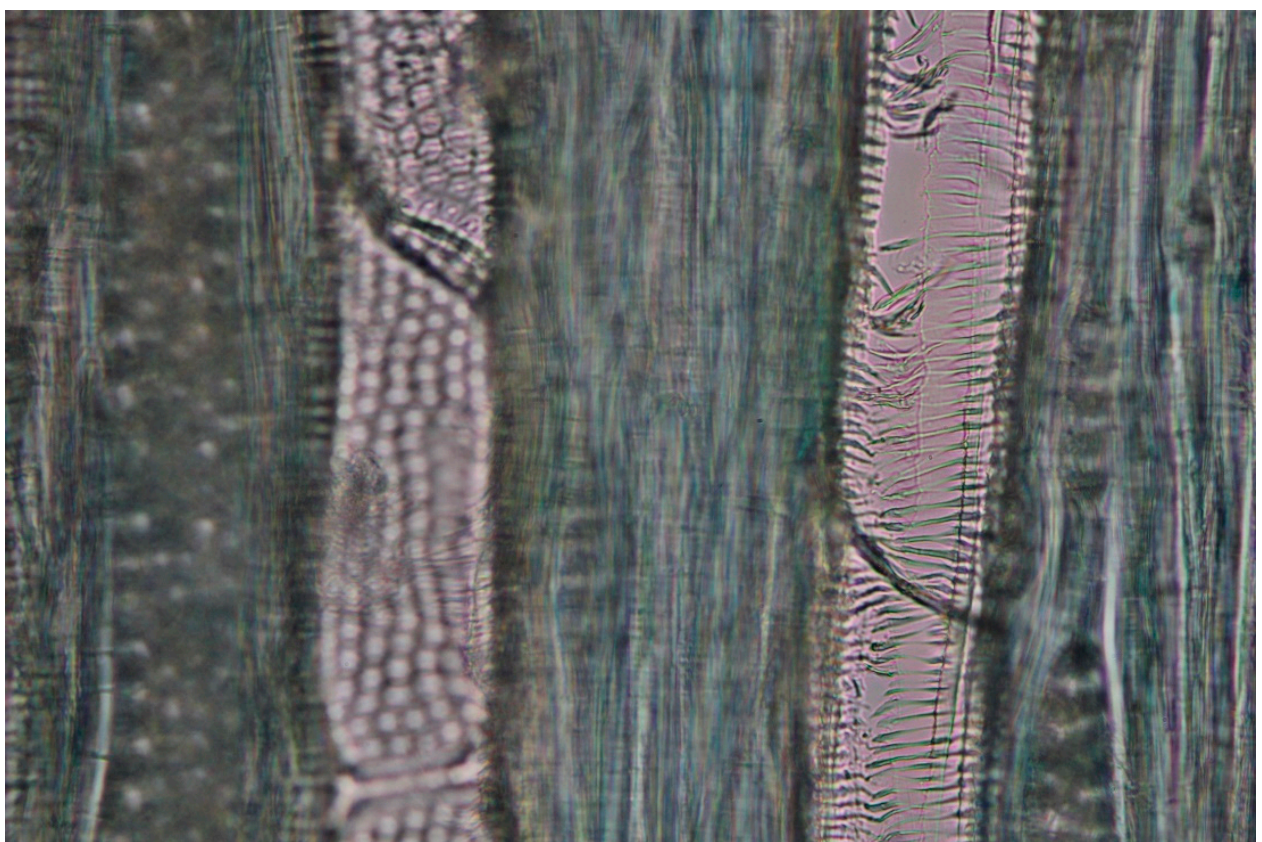

Figure 25. Tangential view of face veneer showing alternate intervessel pitting, spiral thickenings, and cross section of sample perforation plates $(400 \times)$ that are characteristic of sugar maple (Acer saccharum).

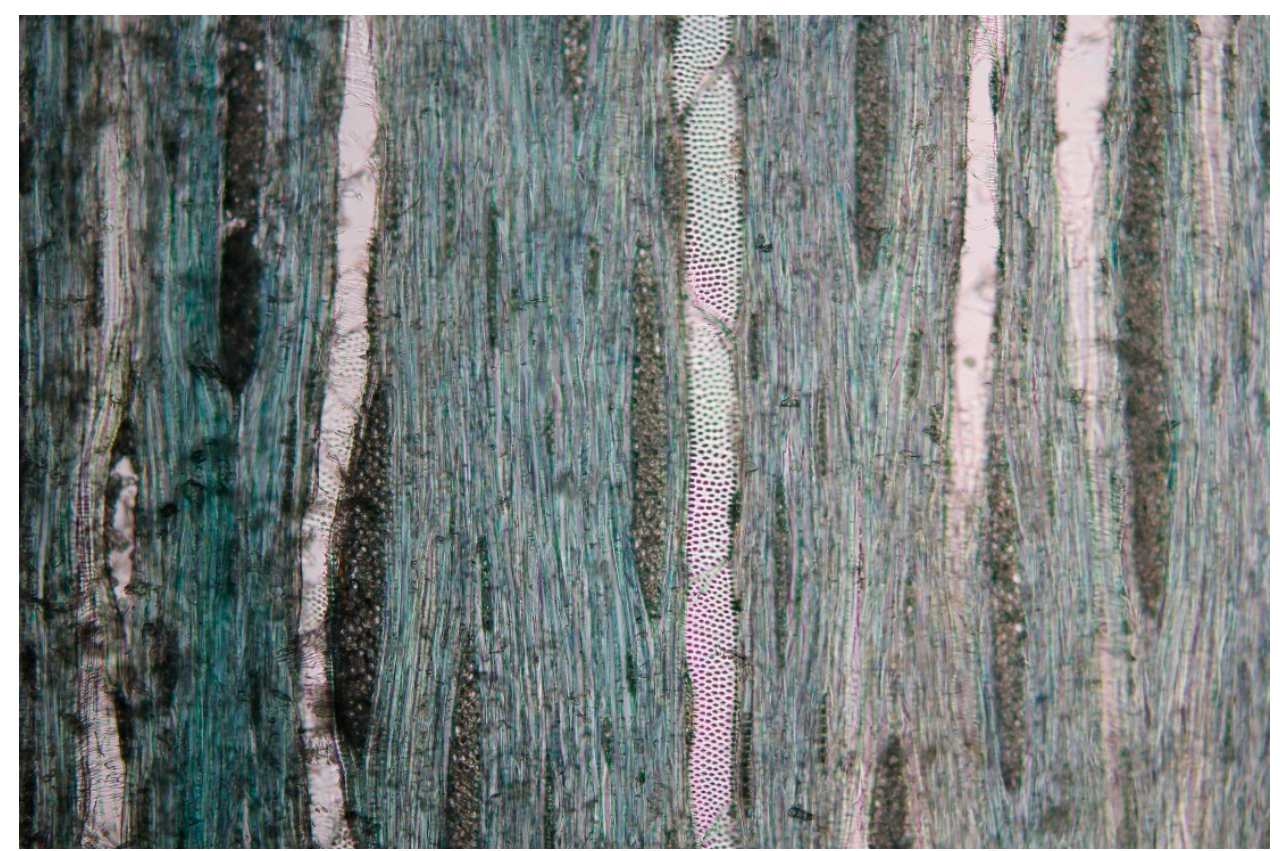

Figure 26. Tangential view of face veneer showing alternate intervessel pitting, spiral thickenings, and cross section of sample perforation plates $(100 \times)$ that are characteristic of sugar maple (Acer saccharum).

\section{Summary and Conclusions}

\subsection{Summary}

It is estimated that millions of skateboards are produced annually and often have a lifetime of only few months because of wear and tear on the deck. The decks of skateboards are typically made of plywood laminated from sugar maple (Acer saccharum) veneers. This paper presents several methods 
of testing material properties for use in reengineering skateboard plywood decks into small panels, which can be used as a raw material for a variety of purposes.

Panels were fabricated from used skateboard decks by a process of initial preparation, sanding, rough sizing, cutting, gluing, and finishing. The curvature of the original skateboard decks was eliminated by selectively sawing strips for laminating the panels.

Because the skateboard panels have a myriad of beautiful colors, many possible applications exist for using the panels. For example, artisans can produce wood composite items such as parquet flooring, furniture, and other artistic creations where color is of interest. This paper demonstrates that panels made from recycled skateboard decks have excellent material properties (Strength (FS) and Stiffness (EI)), which allows them to be utilized in load bearing applications. A limitation of the panels made and tested in this project is their relatively small physical size. However, the strips can be offset or staggered during panel manufacturing to produce larger panels for a wide variety of applications limited only by the imagination of the user.

\subsection{Conclusions}

(1) Strength and Stiffness of the strips in two orientations were measured in third point bending. The average stiffness (EI) of the strips face wise and edge wise were 1,095,000 kg-mm ${ }^{2}$ (3740.9 $\left.\mathrm{lbs}-\mathrm{in} .{ }^{2}\right)$ and 1,396,000 kg-mm ${ }^{2}$ (4771.2 lbs-in. ${ }^{2}$ ) respectively. The average strength (FS) of the strips face wise and edge wise were $1840 \mathrm{~kg}-\mathrm{m}$ (159.7 lbs.-in.) and $2112 \mathrm{~kg}-\mathrm{mm}$ (183.3 lbs.-in.) respectively.

(2) Average moisture content of the skateboard decks at the time of testing was $9.76 \%$. Average specific gravity of the skateboard decks was 0.721 .

(3) Moisture durability tested according to ANSI/HVPA EF 2009 showed that half of the samples failed by delamination. Therefore, adhesives used in skateboard deck manufacturing have poor to moderate moisture resistance. All the test samples had splits which penetrated through the top and bottom veneers.

(4) The species used in all the samples tested was sugar maple (Acer saccharum).

Author Contributions: D.W.: Conception of idea, development and implementation of research plan, fabrication of samples, testing, co-writer of manuscript. J.L.: Project supervisor and advisor, testing, photo micrographs, co-writer of manuscript.

Acknowledgments: The authors would like to give photograph credit to Heather Arnold on Figures 5, 6, 7, 8, 13, $14,15,16,17,18,19$, and 20 in the paper.

Conflicts of Interest: The authors declare there is no conflict of interest.

\section{References}

1. Schmitt, P. (CEO and Founder, Los Angles, CA, USA); Stix, P.S. (Los Angles, CA, USA). Personal Communication, 2017.

2. ASTM D4442. Standard Test Methods for Direct Moisture Content Measurement of Wood and Wood-Based Materials; Annual Book of ASTM Standards 2016; ASTM International: West Conshohocken, PA, USA, 2016.

3. ASTM D2395. Standard Test Methods for Density and Specific Gravity of Wood and Wood-Based Materials; Annual Book of ASTM Standards 2016; ASTM International: West Conshohocken, PA, USA, 2016.

4. American National Standard. American National Standard for Engineered Wood Flooring (ANSI/HVPA EF 2009); Bond Line Test; American National Standard Institute (ANSI): New York, NY, USA, 2009; 12p.

5. Bruce Hoadley, R. Understanding Wood: A Craftsman's Guide to Wood Technology; The Taunton Press: Newtown, CT, USA, 2000; p. 280.

6. The Nitty Gritty Materials. Skateboard Builder Directory, Ministry of Wood. Available online: ministryofwood. com/the-nitty-gritty-materials / (accessed on 21 February 2018). 
(C) 2018 by the authors. Licensee MDPI, Basel, Switzerland. This article is an open access article distributed under the terms and conditions of the Creative Commons Attribution (CC BY) license (http:/ / creativecommons.org/licenses/by/4.0/). 